\title{
On the Translation of Public Sign Expressions
}

\author{
Ning Kang \& Yu Zhang \\ School of Foreign Languages, Qindao University of Science and Technology \\ Qindao 266061, China \\ Tel: 86-532-885-8959Ｅ-mail: kangningkn@163.com
}

\begin{abstract}
English has become an important link in the communication between China and the world; at the same time more and more experts and scholars are paying attention to the translation of Chinese public sign expressions (shortened as PSE) into English. Public signs play a very important role in the life and work of the public. This paper tries to analyze the characteristics and functions of public signs and the linguistic features of English public sign expressions. Some basic translation principles are concluded in the thesis.
\end{abstract}

Keywords: Public sign expressions (PSE), Functions, Linguistic features, Translation principles

\section{Introduction}

With the rapid development of its economy, nowadays China plays a more and more important role in the world. At the same time, English language begins to enter into people's lives as an important way to communicate with the world. Since the 2008 Olympic Games, the XVIII World Congress of the International Federation of Translators (FIT) and World's Exposition are on their way, the government is urging the officials to pay more attention to the translation of public sign expressions. Translating the expressions of public signs needs to be standardized in order to enhance the cultural environment of our country and strengthen the communication with the world.

Public signs refer to words and pictures giving information about people's lives in public places in order to inform, indicate, suggest and warn the public. We can see public signs everywhere. Where there is lodging, traveling, entertainment or shopping, there are public signs. Some public signs aim at encouraging customers to consume.

Public signs help to refine people's social behavior, human relationship, enhance manufacturing efficiency, deter the criminals, raise people's spirit, improve living conditions and help to build a harmonious society. It is very important for us to pay more attention to public signs, especially the translation of them into English in such a crucial period of development of our country. It represents our cultural background and leads our country to enter into the world stage since the world knows better our country through them.

\section{Classification of public signs}

Chinese public signs and English public signs share a lot in common. Both Chinese and English public signs are meant to play the same role in people's lives. According to their functions, public signs can be roughly divided into four kinds, indicative public signs, suggestive public signs, limitative public signs and imperative public signs.

\subsection{Indicative Public Signs}

Indicative public signs are applied to give information to the public without any limitative or imperative suggestion in them. This kind of public signs can be seen almost everywhere in public places. The following are some of them:

"Underground", "Public Toilet", "Information", "Pedestrians"

These public signs do not necessarily require the public to take any particular action. They only provide the public with every piece of information that they might need. Indicative public signs are the most often used and most important public signs in our lives. We can not imagine what our lives would be like without them. For instance, with the development of the economy and the rising of the standard of our life, more and more people would like to spend their holiday traveling all around. In this case, without indicative public signs there to inform us, we may get into a lot of troubles.

\subsection{Suggestive Public Signs}

A suggestive public sign is another kind of widely used public signs. Suggestive public signs are used to give the public some useful suggestions in such places as a park, a supermarket or a hotel.

For example, when coming into a station, probably we may find a sign which reads "For your personal safety and security CCTV is in operation at this station". This public sign does not tell us particularly what we must do or we must 
not do, it just gives us the information to make us feel secured and at the same time gives a suggestion to those who have any idea of committing a crime. The following are some Chinese suggestive public signs:

\subsection{Limitative Public Signs}

Sometimes we may find some public signs such as:

"Handicapped Only"

"Construction Site Keep Out"

"THIS IS A PRIVATE PATH NO ADMITANCE"

This kind of public signs tells what the public should or should not do so as to give instruction to their actions. The language is usually direct but reasonable so that the public can not feel offended and unacceptable.

\subsection{Imperative Public Signs}

Imperative public signs refer to the kind of public signs that forces the public to take certain actions without any place for consultation. This kind of public signs is usually written in a straightforward way with a compelling tone. The public must obey the order if they do not want to get into trouble.

Public signs such as "Police Line Do Not Cross", "No Photography", "NO SMOKING EXCEPT IN DESIGNATED AREAS", “

Imperative public signs are very important in creating a more disciplined and peaceful society by restricting people's actions.

\section{Linguistic Features of English Public Signs}

Although there are many similarities between English public signs and Chinese public signs, English expressions of public signs have their own features. On reading and analyzing some public sign expressions we may easily find some of their linguistic features.

\subsection{Abundant use of noun}

If we take a close look at public signs, especially indicative public signs, we may safely draw a conclusion that there are many nouns used in public signs and most of the indicative public signs are composed of nouns. These nouns can serve to give exactly the information that the public need. Most of them mean to give information about service, indication or instruction. Here are some examples:

\section{"THE CASTLE EXHIBITION"}

"Food \& Beverage"

"Business Center"

\subsection{The use of verbs and gerunds}

Some of the public sign expressions use verbs and gerunds to make the public pay much attention to the actions that they require them to take. Verbs and gerunds are very often used in limitative public signs and imperative public signs.

"KEEP CLEAR"

"NO PARKING"

\subsection{The use of noun phrases and verb phrases}

Noun phrases and verb phrases are usually very easy to understand. Public signs use many noun phrases and verb phrases to make the signs as brief and easy as possible. Here are some examples,

"CAUTION MAINTENANCE IN PROGRESS"

"Cameras in Operation"

"Game Reserve"

\subsection{The use of abbreviations}

Abbreviations are adopted very often in the case that we are so familiar with those public signs that the meaning of them is clear and definite. We do not have to take the trouble to write every word. It saves a lot of space and effort. The public facilities and services that we probably have to use every day use abbreviations frequently.

\subsection{The use of everyday word and simple word}

Public signs are produced to serve the public and the travelers, so their education background should be considered. Uncommon words, jargon, slang, technical terms and archaic words should not be used in public signs in order that they can be understood by almost everyone without any difficulty. Here are some examples: 
"INTERNATIONAL STUDENTS HOUSE"

"NO THROUGH FOR PEDESTRIANS"

\section{"POSITION CLOSED SORRY FOR ANY INCONVENIENCE"}

\subsection{The use of the combination of words and symbols}

In some public places, public signs are composed of words and pictures. Pictures are added to the signs as the complement to give instructions and confirmation so as to make the signs eye-catching and much easier to understand. Here are some examples:

\subsection{The use of present tense}

Public signs only use present tense to give indications, suggestions, limitations or orders because public signs only concern with the actions in their everyday life, what they should always do, yesterday, today or tomorrow, so other tenses are not needed here. Here are some examples:

“THIS TOILET IS OPEN DAILY 7:00AM-7:00PM 7DAYS PER WEEK”

"Smart Water Detection Operates in This Area"

\subsection{The use of imperative sentences}

Public signs are subjected to the public who go out or travel in a hurry doing their business and they certainly do not want to waste a lot of time reading the public signs so imperative sentences are frequently used in public signs. The following are some examples:

\section{"GIVE WAY TO BUSES"}

"Passenger Emergency Alarm Pull Handle to Speak to Driver"

\subsection{The use of set expressions}

Public signs are very important in our lives. Almost every one of us has to use them almost every day. Imagine if there is something improper or sometimes something wrong with the public signs, many people will be influenced. So the most often used public signs in our daily life have become standardized after many years' application. Usually we do not change them even if we have another way to say it and it is absolutely right and proper. There is no problem with this way of expression since it is grammatically right and literally understandable. But we do not use the second one since the previous one has been universally accepted and considered the only way to make the sign even when the other can also be understood without any problem by the public.

\subsection{The use of brief and exact vocabulary}

Public signs are usually very short and precise. We can make them as brief as possible as long as their function to indicate, suggest, limit or give orders can be realized and meanings understood. Therefore, concrete words, key words are enough for public signs and the use of articles, pronouns and auxiliary verbs can be avoided. There are some examples:

"Eurostar International Terminal"

“SORRY, NO CHILDREN STRICTLY OVER 21'S ONLY”

\subsection{The use of public signs with local characteristics}

As we all know, English language has its own variants in America, Britain, Canada or other English-spoken countries. Each country has some characteristics of their own in language. These differences can also be found in public signs. The following is a comparison between some of the public signs with local characteristics:

$\begin{array}{ll}\text { Britain } & \text { America } \\ \text { Underground } & \text { Subway } \\ \text { Mind your Step } & \text { Watch your Step }\end{array}$

\section{Translation Principles}

After a brief introduction of the functions and linguistic features of, now we have a better understanding of English public signs. To translate Chinese public signs into English, knowing this is far away from enough. The translations of public signs into English does not only require us to know the generally used translation principles but also to know the specific principles of public signs according to the characteristics and functions of public signs and the linguistic features. The translation of public signs is very practical. The following are some translation principles often used in the translation of public sign expressions.

\section{1 be easy to understand}

As we have discussed previously, public signs are for the public including those who have not received good education 
and even the illiterate people. If we use big words or difficult words in public signs, they will have difficulty in understanding. Then the use of public signs will become meaningless. Maybe some big words or difficult words can well-represent our culture and education, but public signs are not just for show. No matter how elegant or deep the public sign expressions are, as long as the public can not understand them, they lose their primary meaning and function. We have to take into consideration the functions of the public signs and the public's need. Therefore, we have to make sure that there is no difficult word with which the public may not be familiar when we translate a Chinese public sign expression into English.

\section{2 be definite in meaning}

When we translate the expressions of Chinese public signs into English, we must make sure that the English version must be definite in meaning, no vagueness or ambiguity which may cause problems for the public to understand. Since public signs often give the public directions or explanations so they should be very definite and precise in meaning otherwise the public may get into trouble. In order to give a definite translation, we have to try to find the exact corresponding word in English and make sure there is no misunderstanding or ambiguous interpretation.

\section{3 be brief}

Most of the public sign expressions are very short and sometimes only one word will be sufficient. We should not make the translation too long or wordy since public signs are only supposed to offer the public with necessary and useful information. Too many modifications and explanations only make public signs troublesome and complicated. We do not need to and should not try to translate the Chinese public sign expressions word by word into English. Nobody that is on his way to do business or is in a journey would like to stop by the trouble in reading public signs.

\section{4 be proper in tone}

Different public signs may use different ways of expression according to where they are and to whom they speak to. Some of the public signs sound very gentle and polite, some casual and humorous and some more serious and formal and still some others sound even imposing and compelling. If we want to come up with a good translation we not only need to think about its form and meaning and the public's acceptability but also the tone we use to say it. This is very important because we do not want to be impolite to our guests and customers, and we do not want to be humorous to a man who spit in the street. With a proper tone we can reinforce our ability to express, avoid misunderstanding and make us better understood.

\section{5 use standardized words and avoid Chinglish}

After they have been put into use for several years, some of the words or the way of expression has become standardized and fixed. We can not change them into the way we want. At the same time, we have to avoid word-by-word translation which makes our translation like Chinese. Therefore, we have to find out the similar English usage of the words, phrases or sometimes idiomatic expressions. Even if we may find some other similar expressions in Chinese, we should not use them since there is a commonly accepted way to express in English.

\section{Conclusion}

The translation of public sign expressions has been under a gradual improvement as more and more scholars and experts are taking part in many activities which aim at the modification and standardization of the translation of public sign expressions into English. However, although many improvements are made through these efforts, there is still a long way to go. In order to develop the research in the translation of Chinese public sign expressions, more efforts have to be made.

First, we have to further study the basic translation principles. The language of public sign expressions is very simple and it bears obvious linguistic features. However, as we have to take their particular functions into consideration then the translation becomes much more complicated. The study of basic translation principles is very important for us to standardize our translation of public sign expressions.

Then we have to make a deep research in pragmatics in translation. The study of public signs belongs to social pragmatics. Language using reflects the education background, morality and spirits of the society. The study of translation of public sign expressions can not be separated with the study of pragmatic translation. Pragmatics can give a good explanation of translation and offers us a new respect to solve the problems in translation. The combined study of translation and pragmatics will lead to a new translation principle form and offer the study of translation the instructions of principles and methods. In the translation of public sign expressions, to give an exact expression of what we mean is essential to effective communication. Therefore, one of the problems that we have to solve is to look for the differences of language using between Chinese and English.

Thirdly, we have to set up some standards and rules for the translation of public sign expressions. In order to standardize and improve bilingual public signs, some standards have to be made. With the standards we can avoid divergent translation versions of the same sign and give the translators references and suggestions in the translation 
process.

To build an internationalized metropolis and to integrate with the world, a favorable international language environment is required. Under this environment, it is a crucial and urgent task to make efforts in the research of the translation of public sign expressions and take effective measures to improve the translation. As a translator, the first thing to be considered is the linguistic features and functional significance of the public signs and moreover the analysis of the differences of the cultural characteristics between Chinese and English public signs. The problems that exist in the translation of public sign expressions are not only about the translation techniques but also about the way in which the translators think. Many people think that they can translate as long as they know English. In fact, translation of public sign expressions requires not only knowledge of the foreign language but also the knowledge of the foreign culture. Only with this can we improve the language environment of our country.

\section{References}

Newmark, Peter. (1981). The Theory and the Craft of Translation. Approaches to Translation. New York: Pergamon Press.

Nida, Eugene.A. (1993). Language, Culture and Translation. Shanghai: Shanghai Foreign Language Education Press.

Nord, Christiane. (2001). Translating as a Purposeful Activity: Functionalist Approaches Explained. Shanghai: Shanghai Foreign Language Education Press. 